\title{
PLATE TECTONICS OF ARC-JUNCTION AT CENTRAL JAPAN
}

\author{
Harumi AokI \\ Department of Earth Sciences, Faculty of Science, \\ Nagoya University, Nagoya, Japan \\ (Received March, 4, 1974; Revised April 5, 1974)
}

\begin{abstract}
An investigation into plate tectonics in central Japan is conducted to make it clear what sort of motion is prevailing beneath the junction of IzuBonin and North Honshu arcs. At the beginning, an upper mantle model, consistent not only with deep seismic zones but also with the geometric constraints to the deformation of plate beneath the arc-junction, is proposed.

Negative travel-time anomalies by about 1 second due to the CANNIKIN explosion were observed in the belt in Southwest Honshu, which was also explained quantitatively by this model.

Most of the deep shocks in an isolated area in central part of Honshu were found to be aligned in the NW-SE trend along a range of about $90 \mathrm{~km}$. Their focal mechanism solutions were also almost identical with the model and indicate that the slab is locally under down-dip extension and the average strike of slip-planes may be NW-SE.

These results may suggest the existence of an active fault near the bent edge of slab and that the slab in the southwestern side of the fault moves downwards with respect to the other side to separate the Pacific plate beneath central Japan into two, the Izu-Bonin and North Honshu slabs.
\end{abstract}

\section{Introduction}

Studies of body wave propagation, distribution and focal mechanisms of deep earthquakes etc. have revealed the structure and the motion within the upper mantle beneath island arcs in the northwest Pacific. These studies have also made it clear that the high- $Q$, high- $V$ lithospheric plates are underthrusting beneath island arcs (UTSU, 1971). Northwestern terminal of the Pacific plate forms a series of oceanic trenches along the Kurile, Northeast Honshu and Izu-Bonin arcs. Judging from the existence of a well-defined seismic zone and a developed trench, the Philippine-Sea plate over the west margine of the Pacific plate is also thought to be underthrusting beneath the Ryukyu islands. The Nankai Trough at the northern end of the PhilippineSea plate is also considered to be one of the subduction regions because of the occurrence of huge earthquakes of thrust type along the trough (KANAMORI, 1972). The island arcs seem to be formed by dividing the circum- 
Pacific belt into more or less well-defined discrete segments.

The junctions between these segments are characterized by abrupt changes in trend, differences in seismic activity patterns, remarkable changes in the dip of seismic zone and so on (ISACKS and Molnar, 1971). There are at least three notable arc-junctions in Japan; the Hokkaido corner characterized by down-dip extension of slab and by the difference in dip between the North Honshu and Kurile seismic planes (Isacks and Molnar, 1971); the central part of Honshu near a triple junction of the Pacific, Philippine-Sea and Japan-Sea plates; and the Kyushu corner at the junction of the Ryukyu arc and Southwest Honshu. Among them, the triple junction off central Japan is the most complicated one because three plates are involved in this region. According to Sugimura (1972) and Ando (1972), however, the PhilippineSea plate has not intruded deep into the mantle at this corner but has collided with the land area, so that the existence of the Philippine-Sea plate deep beneath this junction may be ignored. IsACKS and MOLNAR (1971) suggested the hinge faulting in this area, that is, the steeply dipping Izu-Bonin slab tears away and moves downward with respect to the more gently dipping North Honshu slab, and at greater depths the two slabs may be separated. This interpretation seems to indicate a very nature of plate tectonics of the arcjunction. Fortunately in Japan, the density of seismological stations, particularly in central Japan, is sufficiently high to yield more detailed information about the structure of seismic zone, focal mechanisms and the velocity structure within the upper mantle. In the following sections, the writer proposes an upper mantle model from the consideration of plate tectonics at an arc-junction, which can explain not only the particular P-wave travel-time anomaly associated with the bending of slabs but also the distribution and the focal mechanisms of peculiar earthquakes under the central part of Honshu.

\section{Upper Mantle Model beneath an Arc-Junction.}

Because of scanty opportunities for obtaining accurate travel-time data for teleseismic events from various directions, a model of the upper mantle beneath central Japan will be constructed at first on the bases of geometrical relationships concerning the deformation of plate. Other geophysical and geological evidences such as the spatial distribution of deep earthquakes, the disposition of oceanic trenches and that of the volcanic front proposed by SUGIMURA (1960) will also be useful.

The spatial distribution of earthquake hypocenters in and around Japan has been investigated in detail by many authors (e.g., WADATI et al., 1969; Katsumata and SyKes, 1969; KATSUMATA, 1970; IshidA, 1970; UTsU, 1971). 


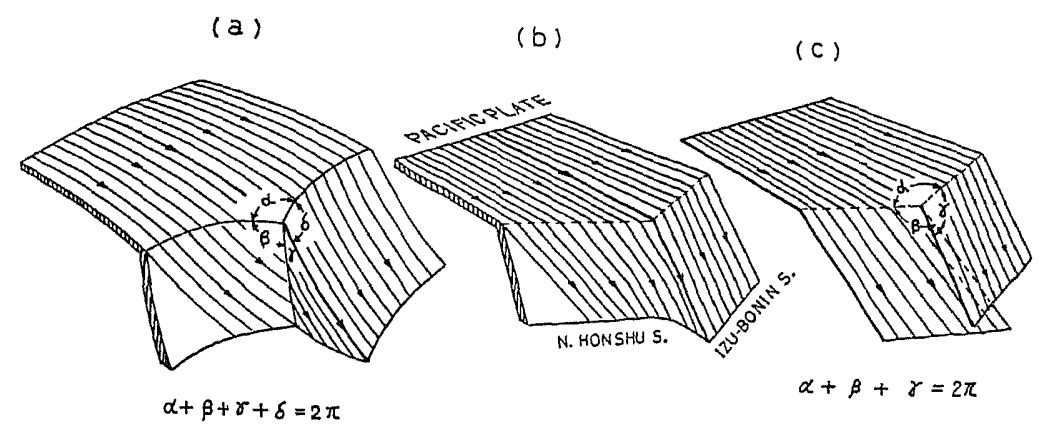

Fig. 1. Possible plate deformations beneath the junction of Izu-Bonin and North Honshu arcs. In each figure, view from the Japan Sea side is schematically shown. Arrows indicate the direction of plate movement. a: deformation of a thin spherical shell. b: deformation without disruption. c: deformation associated with disruption at depths.

According to their studies, the deep shocks beneath the Izu-Bonin arc form a well-defined seismic zone inclined westward with a steep dip in the south and a gentle dip beneath central Japan in the north. Although the seismic activity is low at shallow depths, the surface of an descending slab may be traced from the oceanic trench. In the North Honshu slab, on the other hand, seismic activity is high at shallow depths but too low between depths of 200 and $500 \mathrm{~km}$, which makes it difficult to draw contour lines of seismic zone beneath the Japan Sea. It is still possible, therefore, to modify its configuration at depths more than about $200 \mathrm{~km}$ so as to satisfy the geometrical constraints associated with the plate deformation.

Although there are various types of contortion and disruption of a descending plate (ISACKS and MoLNAR, 1971), the most possible ones for the junction of North Honshu and Izu-Bonin arcs are schematically illustrated in Fig. 1, where the first two are deformations without any disruption, while the last one shows separated slabs after descending. If there is no change in surface area on the descending slab, the Frank's law (1968) should be hold between the dip angle of the slab and the curvature of its surface trace (Fig. 1a). However, the dip angle for most of the island-arcs or arc-like structures seems to deviate considerably from that expected from the curvature of the associated oceanic trench, because the relation between the dip angle and the curvature is greatly affected by the stress state and the physical properties of the descending slab (AOKI, 1974). The more important geometrical restriction on the descending slab is the conservation of surface area at the arcjunction. In Fig. 1, the total sum of the angle at the junction should be $2 \pi$ in order to conserve surface area, due to which one slab at least should be laterally deformed (Fig. 1b) or partly overlapped (Fig. 1c). In view of the 
extremely curved front of active volcanoes in central Japan (see Fig. 2), the most probable one in this region may be of the type depicted in Fig. 1b. It may be reasonable to assume that the boundary between the two slabs orients toward the direction of plate movement being estimated from the slip vectors of large earthquakes near the oceanic trench (IsACKs et al., 1968) or from the relative movements between plates (LE PICHON, 1968). Figure 2 shows the configuration of the upper interface of the high- $Q$, high- $V$ zone beneath central Japan taking into account of the above considerations. Followings are assumed in this figure; 1 ) the hypocenters of deep shocks and the oceanic trench approximately show the upper interface of the descending slab or of the seismic zone; 2) the front of Quaternary volcanoes represents the contour line of seismic activity at $150 \mathrm{~km}$ depth; and 3) the orientation of the boundary between the Izu-Bonin and Honshu slabs is set in the direction of the Pacific

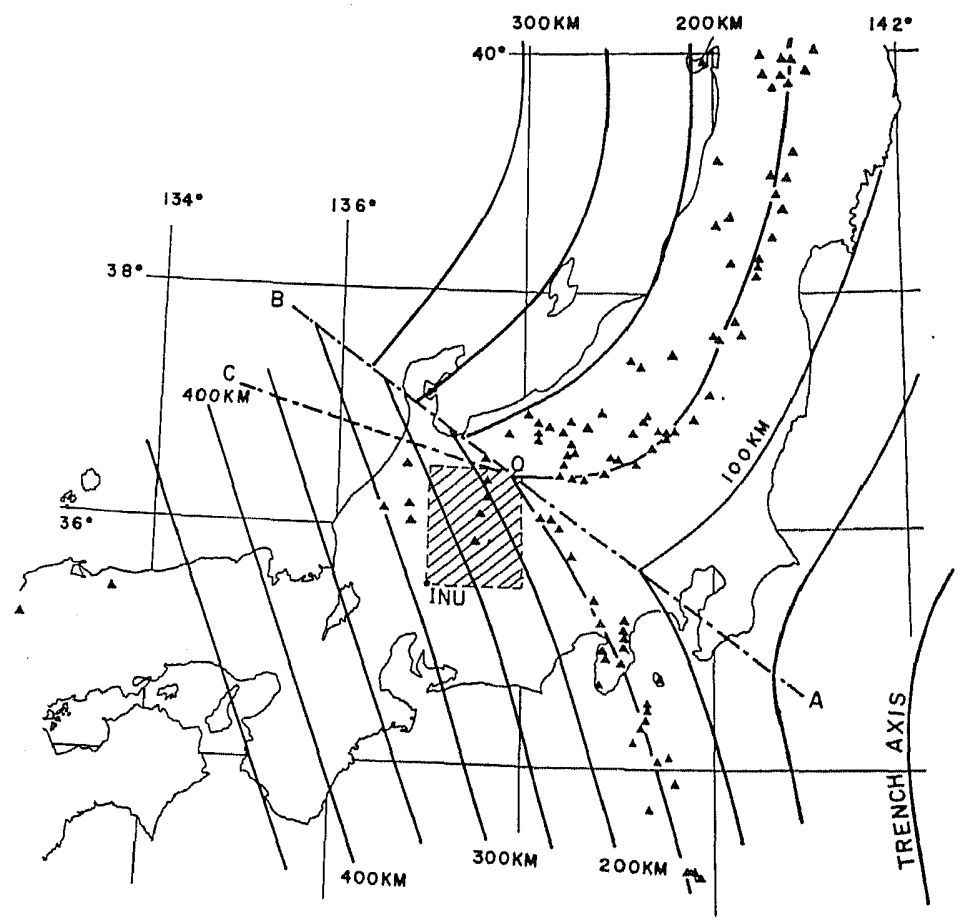

Fig. 2. Proposed model of the upper mantle structure. The upper surface of the high- $Q$, high- $V$ zone is represented by depth contours of $50 \mathrm{~km}$ interval. Triangles: active and Quaternary volcanoes. AOB: northeastern margin of IzLBonin slab. AOC: southwestern margin of North Honshu slab. Note that the direction of $A B$ is oriented parallel to the movement of Pacific plate. Seismic activity in the hatched area enclosed by latitudes $35^{\circ} 30^{\prime} \mathrm{N}$ and $36^{\circ} 30 / \mathrm{N}$ and by longitudes $137^{\circ} \mathrm{E}$ and $138^{\circ} \mathrm{E}$ is shown in Fig. 13 . 
plate movement. It must be noticed that the upper mantle structure thus determined almost satisfies the geometrical constraint of the conservation of surface area on the descending slab. Although there remains an arbitrariness to determine the configuration of the North Honshu slab at depths greater than $200 \mathrm{~km}$, a certain kind of disruption may take place at greater depths. Otherwise, the contortion of the slab becomes so tremendous that the slab may not smoothly penetrate into the deeper seismic zone. Assuming a dislocation between the two slabs at depths more than $150 \mathrm{~km}$, the deeper part of slab may be such a shape as is shown in Fig. 2, where the dashed line OC represents the southwestern edge of the North Honshu slab which dislocates under the condition of surface area conservation.

As the thickness of the high- $Q$, high- $V$ zone under the Honshu arc has not been determined accurately, a tentative thickness of $100 \mathrm{~km}$ is assumed in the present model except for the overlapped region, where the thickness is doubled to represent the volume conservation during the dislocation. The lower interface is expressed by a smooth surface for the convenience of traveltime computation. The velocity difference between the high- $Q$ and low- $Q$ zones was estimated as $6 \%$ by UTsU (1971). A similar result was also obtained by TADA (1972). Although the velocity difference in many instances of slab-like structures has often been assumed to be constant, a slightly different velocity structure as shown in Fig. 3 is used in the present study by the following considerations. In the low- $Q$, low- $V$ zone surrounded the slab, the GUTENBERG's velocity distribution (1959) with a low velocity character in the asthenosphere may be adopted at depths greater than $100 \mathrm{~km}$. At

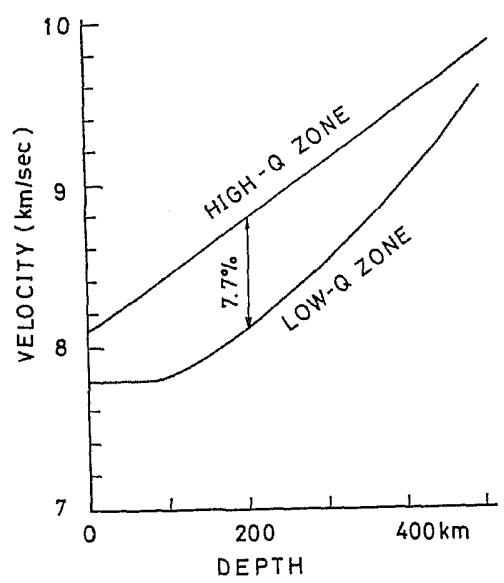

Fig. 3. P-wave velocity models used in this paper for the high- $Q$, high- $V$ zone and of the surrounding mantle. 
shallow depths, however, a constant value of $7.8 \mathrm{~km} / \mathrm{sec}$, the representative $P_{n}$ velocity in central Japan (AoKI et al., 1972), is used. It has also been suggested by AKI (1961) that the upper boundary of the low velocity layer in Japan seems to be the Moho discontinuity. Within the slab, velocity was assumed to increase linearly from the normal $\mathrm{P}_{n}$ velocity to the velocity corresponding to that in the surrounding mantle materials deeper than $600 \mathrm{~km}$ (see Fig. 3).

\section{P-wave Travel-Time Anomaly}

As the upper mantle structure described in the preceding section is no longer approximated by a two-dimensional model, a fast program of traveltime computation in a heterogeneous medium has been developed by the use of an earth-flattening technique for body waves, which has been applied to the media with spherical symmetry. Exact transformations of depth and velocity giving the identical travel-time for both the spherical and flat systems are represented by HILL (1972) as

$$
\begin{aligned}
x & =a \cdot \Delta \\
z & =a \cdot \log (a / r) \\
V_{f} & =V_{s} \cdot a / r
\end{aligned}
$$

where $x$ and $\Delta$ is respectively epicentral distance in the flat and spherical system, $a$ is the earth's radius, $V_{f}$ is the velocity at a depth of $z$ in the flat system and $V_{s}$ is the velocity at a radial coordinate $r$. Since the geometrical transformation represented by the first two in (1) is isogonal with respect to the $x-z$ plane, i.e., any angle in one system is transformed into the other without any change, the transformation is still exact in laterally heterogeneous media so far as the ray path in the spherical system is on the plane of great circle passing through the source and the receiver.

In case of a general heterogeneous structure, in which a path deviates from the plane of great circle, the travel-time derived from the earth-flattening technique is no longer exact but bears an error due to the distortion of ray path. Because the isogonal character of (1) does not hold on a spherical surface. Suppose two points with spherical coordinates $(r, \Delta, \varphi)$ and $(r$, $\Delta+\delta \Delta, \varphi+\delta \varphi)$, where $\delta \Delta$ and $\delta \varphi$ are small quantities. Then, the distance between the two points is given by

$$
r \sqrt{(\delta \Delta)^{2}+(\delta \varphi \cdot \sin \Delta)^{2}} \text { in the spherical system, }
$$

which is transformed into

$$
r \sqrt{(\delta \Delta)^{2}+(\delta \varphi \cdot \Delta)^{2}} \text { in the flat system . }
$$

Therefore, the ray paths which are deviating from the plane of great circle 
are distorted by factors not greater than $\Delta / \sin \Delta$. Accordingly, it is necessary to restrict the use of the transformations within a small range of $\Delta$ in order to obtain accurate travel-times. This restriction, however, is not serious for teleseismic events, because the region containing the anomalous velocity structure seems to be confined to the crust and upper mantle. Instead of full calculations from a source to receivers, a number of travel-times and incident angles at a certain depth, say, $600 \mathrm{~km}$ below the surface, are calculated by the use of conventional one-dimensional techniques. Thus calculated quantities are used as the inputs to the laterally heterogeneous region within a limited area. After the transformation of this limited region in to a flat system, the velocity structure is approximated by several blocks or otherwise layers of

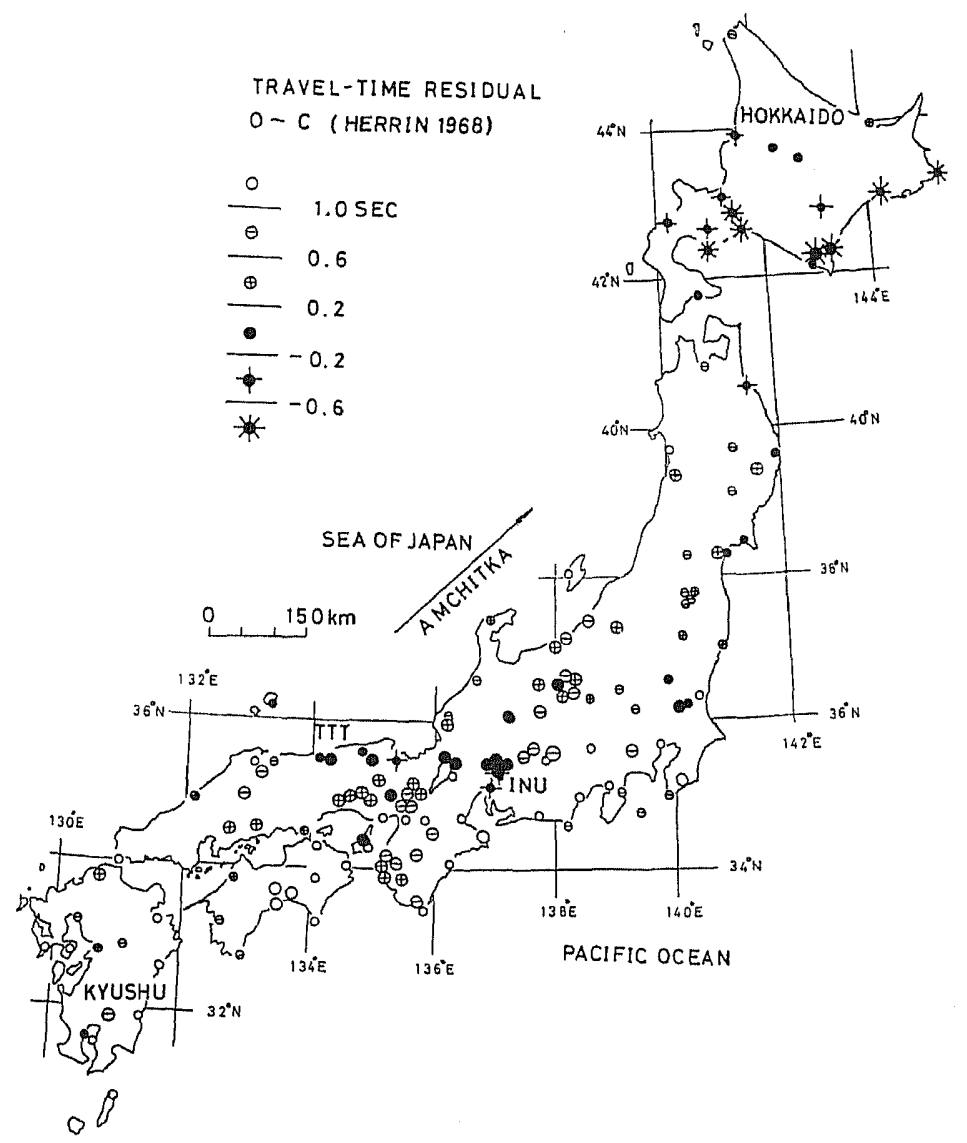

Fig. 4. Distribution of travel-time anomalies of P-waves from the CANNIKIN event (epicenter; $179.107^{\circ} \mathrm{E}, 51.472^{\circ} \mathrm{N}$, depth; $1.791 \mathrm{~km}$, origin time; $22: 00: 00.1$ GMT on Nov. 6, 1971). Residuals O-C from Herrin's tables (1968) are plotted by large symbols (university stations) and small ones (JMA stations). 


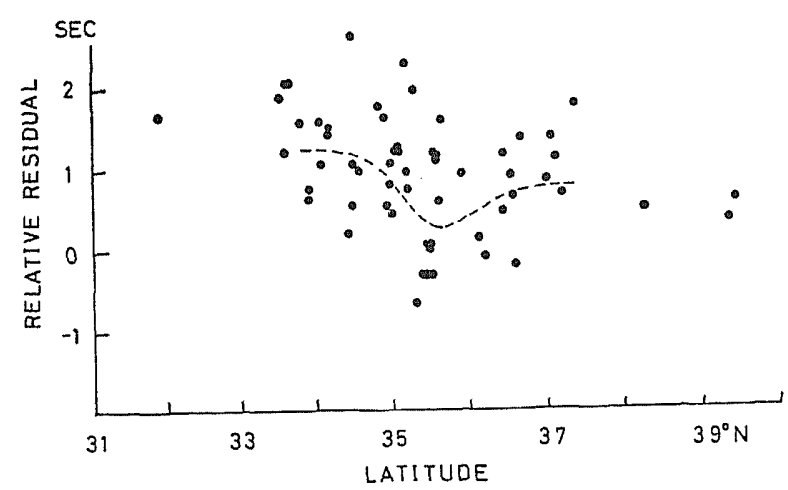

Fig. 5. P-wave travel-time residuals plotted against latitude. Dashed line; computed residuals for the region where anomalies are prominent.

arbitrary shape and size each of which is characterized by depth-dependent velocities. Furthermore, each block or layer is approximated by a sequence of horizontal layers. In every constituent layer, the velocity is assumed to vary linearly with depth so that the ray path turns out to be a circle and the travel-time as well as the path can be represented by a simple formula (e.g., DoBRIN, 1960). At interfaces of blocks or layers, the ray tracing technique developed by Sorrells et al. (1971) was adopted in the present study.

This technique was eventually applied to the CANNIKIN explosion detonated on Amchitka Island on November 6, 1971, for interpreting P-wave data at Japanese stations which are located southwest at epicentral distances between $26^{\circ}$ and $41^{\circ}$. Figure 4 shows the distribution of $\mathrm{P}$-wave arrival time anomalies compiled by AOKI and TADA (1973) in terms of travel-time residuals relative to the HERRIN's tables (1968). As shown in this map there are several anomalous regions in Japan. Some of these regions are easily explained by the well-known, two-dimensional plate tectonics. The following two, however, are not consistent with this simple theory; one is the delayed arrival region near the Nankai Trough, which shows a contradictory pattern to that in Hokkaido. Another one is a narrow but a distinct belt of early arrival region extending east to west from central to southwestern Japan along a latitude of $35.5^{\circ} \mathrm{N}$. Though the contrast of arrival time's anomaly to those outside the belt is only about $1 \mathrm{sec}$, as small as local residuals for teleseismic events, an exceptionally dense distribution of sensitive stations revealed undoubtedly the existence of a special belt. A part of this anomalous belt has really been reported by KANAMORI $(1968,1970)$ for other nuclear explosions fired at Amchitka Island and at Nevada. Considering the orientation of the anomalous belt, the $\mathrm{P}$-wave residuals in Japan, except for Hokkaido, are plotted against latitude as shown in Fig. 5. The delayed arrivals 
in low latitudes represent partly the anomalous region in Kyushu which may be associated with the low- $Q$, low- $V$ zone over the descending Philippine-Sea plate, and partly those near the Nankai Trough, which might be related to the high heat flow pattern reported by UYEDA (1972), so that the early arrivals observed in the belt are most noticeable for the study of velocity structure in this region. Because of long distances from CANNIKIN to the stations and of the existence of an anomalous structure beneath Aleutian Islands (SLEEP, 1973), only variation of travel-time anomaly will be taken into account.

The surface of the high velocity slab in Fig. 2 is expressed in terms of depth $z_{i j}$ at grid points $\left(x_{i}, y_{j}\right)$, spacing $50 \mathrm{~km}$, with $x-y$ plane on the earth's surface with origin at the center of Honshu. The depth at an arbitrary point $(x, y)$ is approximated by the equation $z=a x+b x y+c y+d$, where $a, b, c$, and $d$ are the constants determined from the condition that the equation is satisfied at the four grid points around the point $(x, y)$. The thickness of the slab and the velocity structure in the mantle were so taken as has been described in Section 2. The calculated results of $P$-wave travel-times are shown in Fig. 6, where only relative values are contoured with an interval of $0.2 \mathrm{sec}$. The

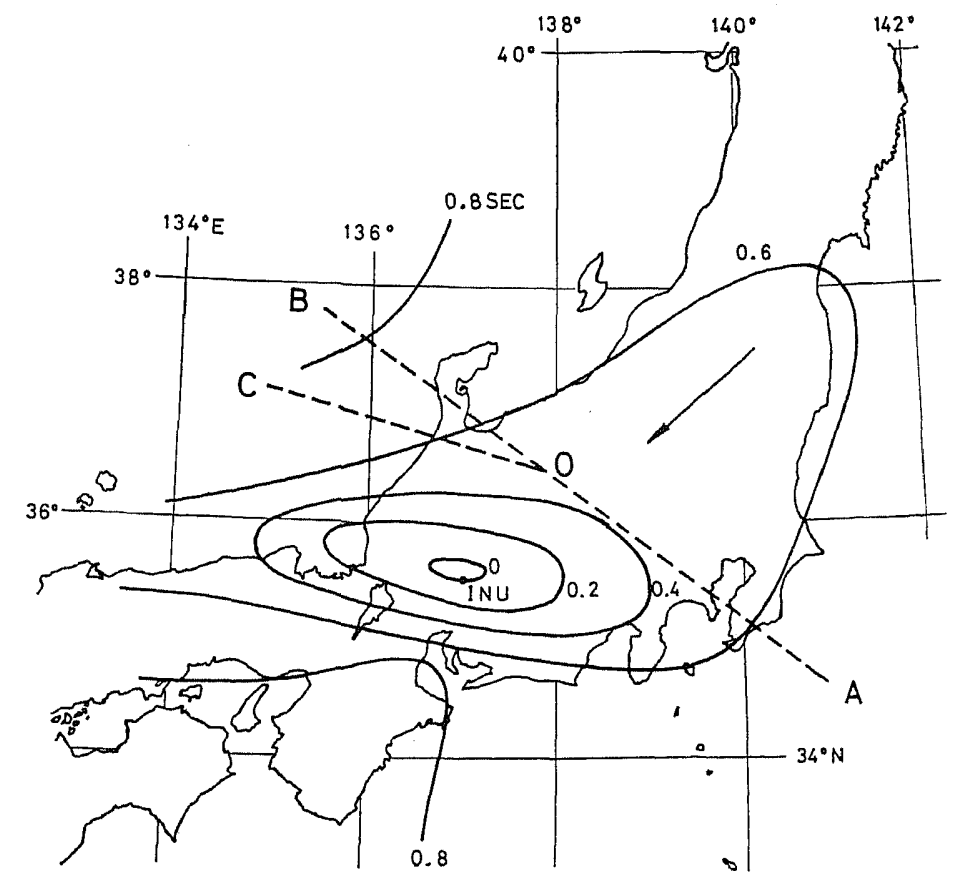

Fig. 6. P-wave travel-time residuals calculated from the model shown in Figs. 2 and 3 . Only relative values are shown in this figure. Arrow; average direction of incident waves from CANNIKIN. 
arrow in this figure indicates the average direction of incident waves, and the dashed line $\mathrm{AB}$ and $\mathrm{OC}$ are the boundaries of slabs as indicated in Fig. 2. Comparing this with Fig. 4, we can find a good agreement between the computed and the observed results for the anomalous belt in the central and southwestern Japan. To the east of INU, however, the computed anomaly extends eastwards beyond the region where no early arrival is observed. The seismic waves in this area are supposed to have passed through the zone beneath the volcanic chain which extends northwards along the Izu-Bonin arc. If the upper mantle beneath the volcanic chain is generally characterized by a prominent low- $Q$ zone (GROW and QAMAR, 1973), the discrepancy between the computed and the observed results in this area may be due to the low- $V$ character associated with the low- $Q$ zone. The residuals $\mathrm{O}-\mathrm{C}$ along the longitude of $137^{\circ} \mathrm{E}$, where the anomalous feature is most prominent, are shown by a dashed curve in Fig. 5 comparing to the observed data. In this figure, a certain amount of shift parallel to the residual axis has been made so that it gives the best fit to the observed data, since only relative anomalies

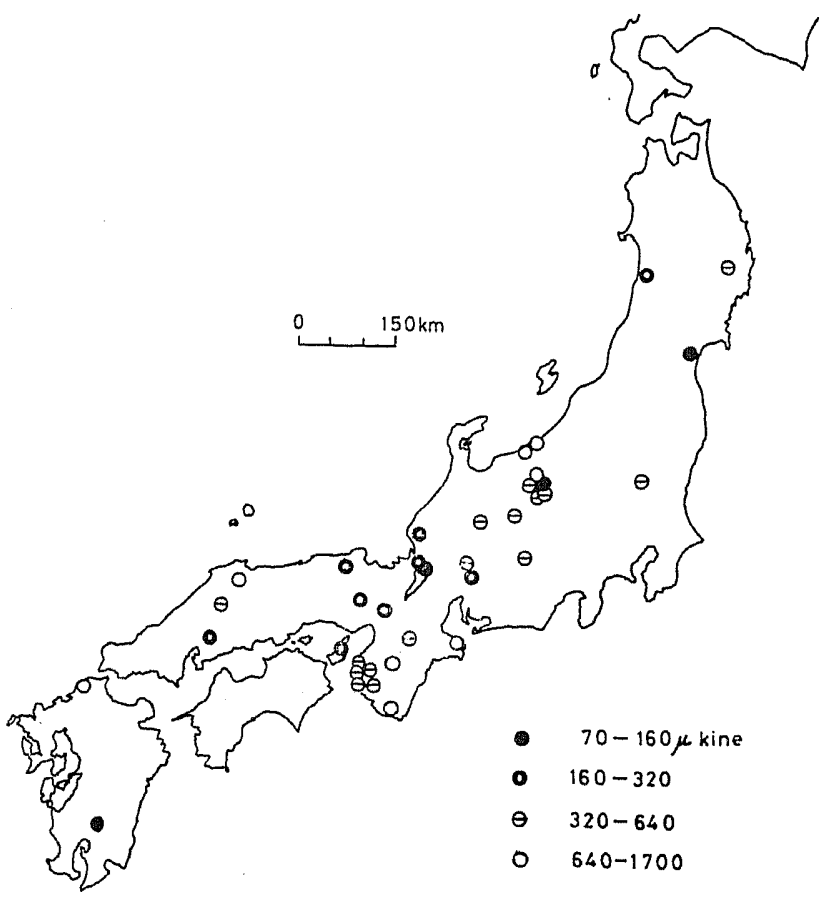

Fig. 7. Distribution of first-peak-velocity-amplitudes of P-waves from CANNIKIN. The frequency response of recording system for ground velocity is flat between $1 \mathrm{~Hz}$ and $30 \mathrm{~Hz}$. 


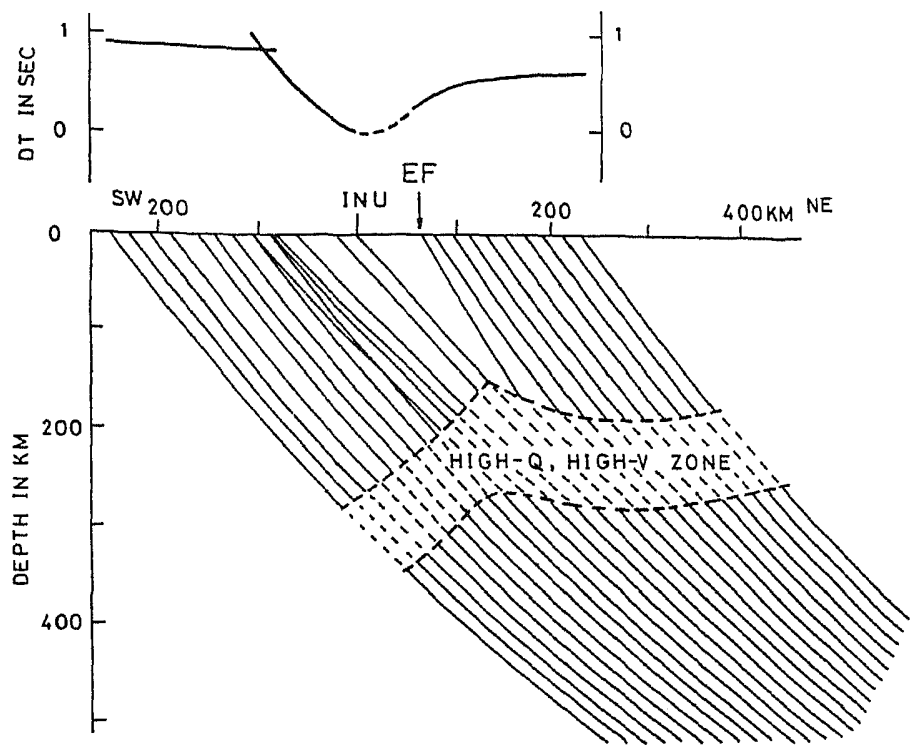

Fig. 8. Illustration of ray paths which pass through the particular structure shown in Fig. 2. The dotted parts of the ray paths indicate the propagation of P-waves through the high- $Q$, high- $V$ zone. Note that the boundaries of high- $Q$, high- $V$ zone do not imply the cross section of slab because the paths are not parallel to the vertical plane especially in the slab. Curves in the upper figure are the theoretical variation of P-wave arrival times DT along the paths in the lower figure. EF; location of active fault shown in Fig. 13.

have been calculated. A nice agreement between the theory and the observation is recognized in this figure.

A supplemental evidence for the anomalous structure beneath the central part of Honshu is also given by the amplitude study of P-waves from CANNIKIN. In Fig. 7, the first-peak-amplitudes of ground velocity (for P-waves) measured at many sensitive stations (AOKI and TADA, 1973) are plotted with four different symbols. Stations where P-waves have small amplitudes seem to be clustered in the anomalous region which we are now discussing. In Fig. 8, some of the ray paths passing through the anomalous structure beneath central Japan are projected onto the vertical plane oriented at NE-SW. As shown in this figure, seismic waves propagating toward the bent edge of the high- $V$ zone are characterized not only by the long paths in the zone, which decreases travel-time remarkably but also by the divergent character of refracted rays at the bent edge of the zone. Therefore, it may be concluded that P-waves in the region of early arrivals of this type is generally characterized by small amplitudes. Furthermore, in the overlapped region bounded by $O B$ and $\mathrm{OC}$ on the slab (see Fig. 2) at depths greater than about $150 \mathrm{~km}$, scatter 


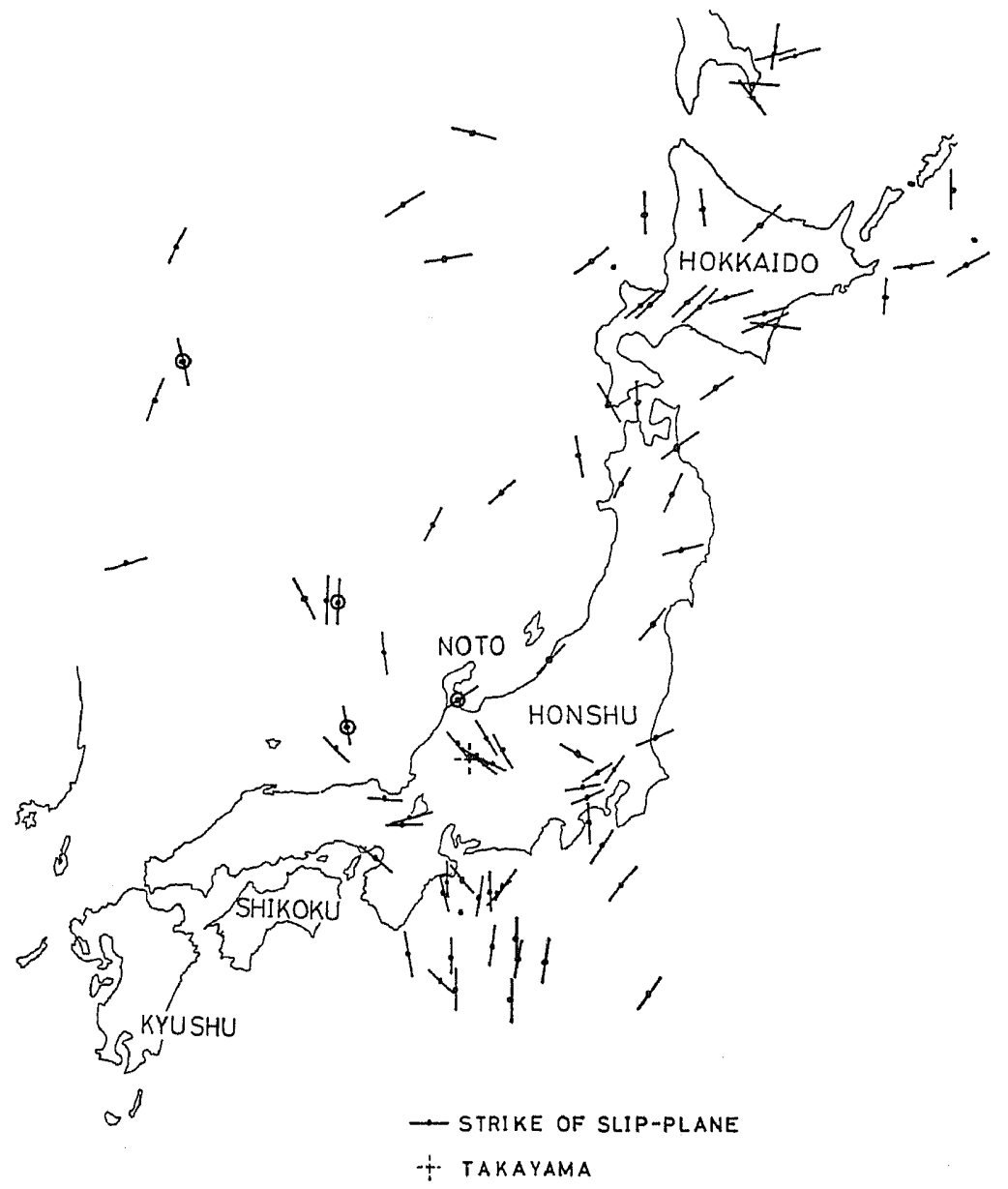

Fig. 9. Distribution of strikes of the steeply dipping nodal planes with dips greater than $70^{\circ}$ for deep and intermediate (depth $\geqq 100 \mathrm{~km}$ ) earthquakes occurred in the Izu-Bonin and North Honshu slabs. Solid circle with a short bar; data due to ICHIKAwA (1971). Double circle with a short bar; data due to the present author.

of seismic waves due to curved interfaces may take place as well. Thus the tendency that appears in Fig. 7 may be in favor of the present model, although more data are required to make a concrete conclusion from the amplitude study of P-waves.

\section{Focal Mechanism Solution}

Recent studies on focal mechanism solutions (e.g., Honda et al., 1967; Katsumata and Sykes, 1969; IChIKAWA, 1971; and IsaCKs and MolNar, 
1971) have indicated that the stresses involved in deep and intermediate earthquakes beneath Honshu and the Izu-Bonin arc are generally characterized by down-dip compression, except for those in central part of Honshu, where the Izu-Bonin and North Honshu slabs are supposed to join and form a particular structure as was depicted in Fig. 2. FUKAO (1974), investigating the nature of multiple and/or aftershocks within the mantle, concluded that the slip-plane is almost vertical in the inclined seismic zone for either case of down-dip compression or extension. Refering to his conclusion, the focal mechanism solutions obtained by ICHIKAWA (1971) for deep and intermediate earthquakes in and around Japan from 1926 to 1968 have been re-examined. The results are shown in Fig. 9. A few solutions obtained by the present writer for earthquakes after 1969 are also added in this figure. For most of these events, one of the two nodal planes has a dip angle as large as $70^{\circ}$ or more and the strikes of such nodal planes are distributed with systematic alignment parallel to the offshore trenches in southern Izu-Bonin arc, Northeast Honshu, and Hokkaido.

At the northern part of the Izu-Bonin slab, however, many earthquakes seem to cluster around a few spots with the orientations of slip-plane that are characteristic of respective clusters. Among these clusters, those earthquakes in the vicinity of Takayama, which are provisionally named "Takayama deep shocks", are characterized by down-dip extension and the strikes of their steeper nodal planes are equally oriented at NW-SE, i.e., the southwestern side moves downward relative to the northwestern side. As hypocenters are close to the North Honshu slab, the idea of hinge faulting suggested by Isacks and Molnar (1971) may be worthy to be tested in more detail with the use of both their focal mechanism solutions and the spatial distribution. Fortunately, the Japanese stations are situated on very important locations to discriminate the earthquakes of this type from others
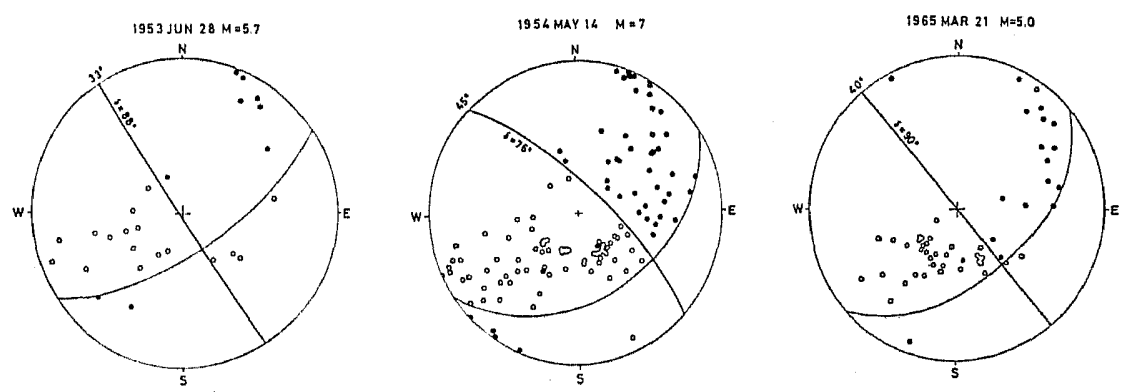

Fig. 10. Focal mechanism solutions of Takayama deep shocks are illustrated in equal-area projections of the upper hemisphere of the focal sphere. Solid and open circles indicate compressional and dilatational first motions, respectively. 
even for small magnitudes less than 5. The JMA data (1927-1970), ISC data (1964-1970 Sept.) and many available data from the sensitive stations operated by Japanese Universities (1965-1970) have been investigated along this line, particularly for determining the orientations of steeper nodal planes that are expected to appear in central Japan; first motions are downward in the western half and upward in the eastern half of Japan with the boundary oriented at NW-SE. P-wave first motions are illustrated in Fig. 10 in equalarea projections of the upper half of the focal sphere. Their distributions are surprisingly similar to each other but are distinctly different from those in other regions (e.g., IcHIKaw A, 1971) where the strike of slip-plane, or the steeper nodal plane of the two, is generally parallel to the nearest oceanic trench and the stress state in the slab is characterized by down-dip compression. Conversely speaking, the earthquakes with focal mechanisms of downdip extension and steeply dipping nodal planes with NW-SE strike are really all located under the Takayama region at depths from 200 to $300 \mathrm{~km}$ (Fig. 11). It is noted in Fig. 11 that the earthquakes of intermediate type are very few in the vicinity of the Takayama region. Furthermore, the strike as shown in Fig. 9 seems to chrnge abruptly near the boundary between the two slabs.

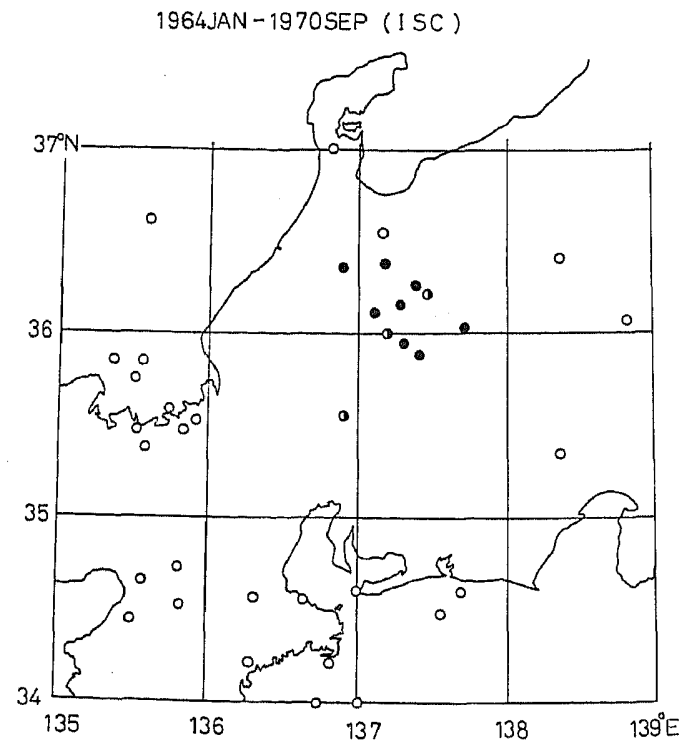

Fig. 11. Epicenters of deep and intermediate earthquakes reported by ISC (1964-1970 Sept.). Solid circles; events with similar focal mechanisms as those shown in Fig. 10. Open circles; events with focal mechanisms different from those shown in Fig. 10. Half-solid circles; events whose focal mechanisms are unknown. 
Hence it appears that the occurrence of Takayama deep shocks have been closely related to the downward movement of Izu-Bonin slab relative to the southwestern end of North Honshu slab as suggested by Isacks and Molnar.

\section{Spatial Distribution of the Takayama Deep Shocks}

As described in the preceding section, the Takayama deep shocks seem to be related to the hinge faulting movement between the two slabs. If so, hypocenters should have been located on or near the fault plane constituting a part of the boundary between the two slabs, or at least, their spatial distribution should be consistent with the anomalous structure as shown in Fig. 2. In order to make it sure, a special technique for the precise determination of hypocenters is necessary. This problem has the troubles mainly in the accuracy of arrival times especially before nineteen-fifties, and also in the local irregularities which may exist in the crust and upper mantle structures. In order to avoid these troubles, the following method, basically similar to that developed by FUKAO (1972), was adopted in determining the relative locations of clustered shocks.

In Fig. 12, $\mathrm{P}_{i}$ and $\mathrm{P}_{j}$ denote the $i$-th and $j$-th hypocenters of clustered shocks, respectively. $\mathrm{S}_{m}$ is the $m$-th station that observed both events $\mathrm{P}_{i}$ and $\mathrm{P}_{j}$ at a far distance as compared with the space between the two. Then it follows that the directions of ray paths toward $S_{m}$ are almost the same and the difference in path $\delta L_{m}$ is expressed in terms of the direction cosines

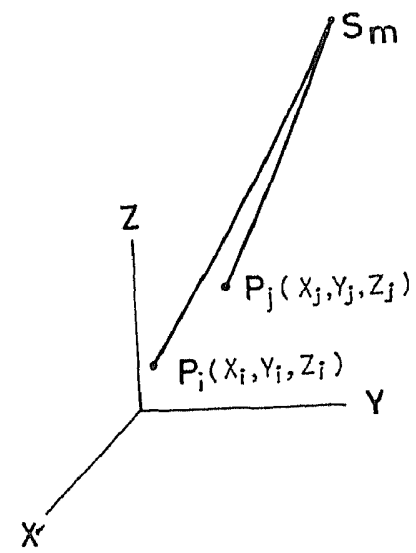

Fig. 12. Geometry of sources and a receiver. $\mathrm{S}_{m}$; location of $m$-th receiver on the earth's surface. $\mathbf{P}_{i}$ and $\mathrm{P}_{j}$; locations of two events, the spacing between which is sufficiently small compared with ray paths $\mathrm{P}_{i} \mathbf{S}_{m}$ and $\mathbf{P}_{j} \mathbf{S}_{m}$. The direction cosines of ray paths to $\mathrm{S}_{m}$ are given as $\left(l_{m}, m_{m}, n_{m}\right)$ near the source. 
$\left(l_{m}, m_{m}, n_{m}\right)$ for both rays $\mathrm{P}_{i} \mathrm{~S}_{m}$ and $\mathrm{P}_{j} \mathrm{~S}_{m}$, and of the coordinates $\mathrm{P}_{i}\left(x_{i}, y_{i}, z_{i}\right)$ and $\mathrm{P}_{j}\left(x_{j}, y_{j}, z_{j}\right)$ as

$$
\delta L_{m}=l_{m}\left(x_{j}-x_{i}\right)+m_{m}\left(y_{j}-y_{i}\right)+n_{m}\left(z_{j}-z_{i}\right)
$$

On the other hand, $\delta L_{m}$ can be represented by either S-P time or P-wave travel-time as

$$
\delta L_{m}=k \cdot\left(\tau_{m i}-\tau_{m j}\right)
$$

or

$$
\delta L_{m}=v \cdot\left(t_{m j}-t_{m i}\right)-v \cdot\left(o_{i}-o_{j}\right)
$$

where $k$ and $v$ are the Omori's constant and the P-wave velocity in the region of hypocenters; $o_{i}$ is the origin time of $\mathrm{P}_{i} ; t_{m i}$ and $\tau_{m i}$ are the $\mathrm{P}$-wave arrival time and the S-P time both observed at $\mathbf{S}_{m}$ for the event $\mathbf{P}_{i}$, respectively. The similar notations are also used for the event $P_{j}$. Since the constants $k$ and $v$, and the direction cosines for each station are given from a suitable earthmodel with spherical symmetry, the relative locations of hypocenters as well as the differences in origin times are easily obtained from the linear equations (2) with use of the least square method. The choice of (3) or (4) in solving (2) was made depending on the accuracy in arrival times. When the timekeeping at each station was not good, S-P times were used for $\delta L_{m}$. Generally

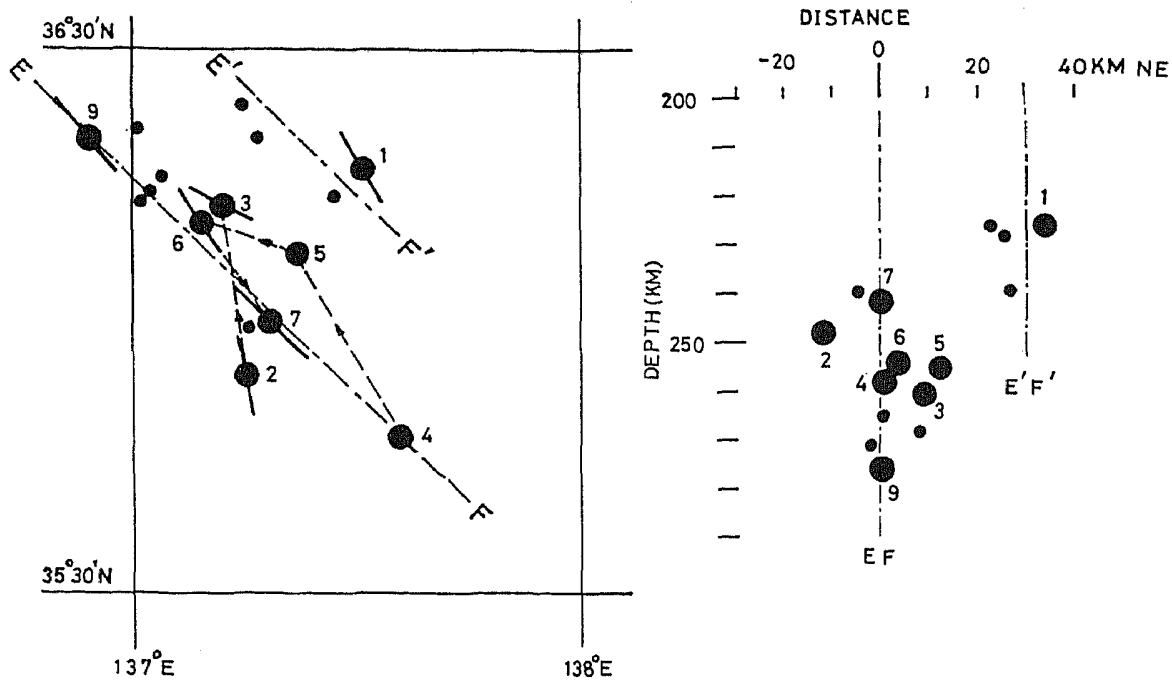

Fig. 13. The revised hypocenters of Takayama deep shocks. Left figure: epicenters. Short thick lines; strikes of steeper nodal plane for the events whose focal mechanism solutions are well determined. Large circles; $M \geqq 5$. Small circles; $M<5$. Dashed line with an arrow; the earthquake sequence. Right figure; projection of hypocenters onto the vertical plane perpendicular to EF. 
speaking, the time accuracy after 1964 are good enough to allow the use of arrival times. Therefore, the relative locations of recent shocks, even for small ones, are so accurate as about $\pm 5 \mathrm{~km}$, whereas those of other shocks determined from S-P times are less accurate but their errors are still not more than about $10 \mathrm{~km}$. Hypocenters relative to that of 1965 thus determined are listed in Table 1, where the notations PS and P refer to the uses of S-P times and $\mathrm{P}$-wave arrival times, respectively. The magnitudes of these shocks determined by KATSUMATA (1970), ISC and USCGS are also given in the table. The magnitude of the event No. 1 is determined by the Katsumata's method. These hypocenters and the well-determined strikes of slip-plane are plotted in Fig. 13 with large $(M \geqq 5)$ and small $(M<5)$ symbols. The focal mechanisms of these events seem to be all alike or, at least, do not contradict to the theory. As can be seen in this figure, most of the large shocks $(M \geqq 5)$ are well aligned along a line EF that is parallel to the bent edge of slab shown in Fig. 2. The range of distribution may be more than $90 \mathrm{~km}$ along EF. A large shock No. 1 is an exceptional one which is located about $30 \mathrm{~km}$

Table 1. List of Takayama deep shocks, 1927-1970.

\begin{tabular}{|c|c|c|c|c|c|c|c|c|c|c|c|}
\hline \multirow[t]{2}{*}{ No. } & & \multicolumn{3}{|c|}{ Date (GMT) } & \multicolumn{3}{|c|}{$\begin{array}{l}\text { Hypocenters relative to } \\
\text { that of No. } 9 \text { (in km) }\end{array}$} & \multirow{2}{*}{$\begin{array}{l}\text { Method } \\
\text { of } \\
\text { compu- } \\
\text { tation }\end{array}$} & \multirow{2}{*}{$\begin{array}{c}\text { Number } \\
\text { of } \\
\text { data* }\end{array}$} & \multirow{2}{*}{$\underset{\substack{\text { First } \\
\text { motion }}}{\underbrace{}_{* *}}$} & \multirow{2}{*}{$\begin{array}{l}\text { Magnitude } \\
\text { (Source) }\end{array}$} \\
\hline & & $\mathrm{d}$ & $\mathrm{h}$ & $\mathrm{m}$ & $\mathrm{E}$ & $\mathrm{N}$ & $\mathrm{U}$ & & & & \\
\hline 1 & 1927 Nov. & 10 & 19 & 48 & $55 \pm 7$ & $-6 \pm 10$ & $51 \pm 4$ & PS & 14 & $7 \mathrm{D} 10 \mathrm{C}$ & $5(\mathrm{~A})$ \\
\hline 2 & 1931 Jun. & 2 & 2 & 38 & $32 \pm 8$ & $-49 \pm 10$ & $28 \pm 4$ & PS & 16 & $18 \mathrm{D} 16 \mathrm{C}$ & $6 \frac{1}{4} 6 \frac{1}{2}(K)$ \\
\hline 3 & 1935 Apr. & 15 & 11 & 15 & $27 \pm 5$ & $-13 \pm 7$ & $16 \pm 3$ & PS & 29 & 27D10C & $6 \frac{1}{4}(K)$ \\
\hline 4 & 1951 Dec. & 6 & 19 & 21 & $63 \pm 6$ & $-61 \pm 8$ & $19 \pm 4$ & PS & 23 & $6 \mathrm{D}$ & $5(\mathrm{~K})$ \\
\hline 5 & 1953 Feb. & 27 & 22 & 3 & $42 \pm 11$ & $-24 \pm 13$ & $21 \pm 6$ & PS & 9 & $2 \mathrm{D}$ & $5(\mathrm{~K})$ \\
\hline 6 & 1953 Jun. & 28 & 14 & 43 & $23 \pm 4$ & $-17 \pm 5$ & $22 \pm 3$ & PS & 40 & 17D9C & $5(\mathrm{~K})$ \\
\hline 7 & 1954 May & 14 & 22 & 39 & $36 \pm 7$ & $-38 \pm 8$ & $34 \pm 4$ & PS & 42 & 96D55C & $7(\mathrm{~K})$ \\
\hline 8 & 1964 Jul. & 30 & 2 & 31 & $34 \pm 5$ & $0 \pm 6$ & $50 \pm 5$ & $\mathbf{P}$ & 15 & $4 \mathrm{D}_{2} \mathrm{C}$ & 3.8 (ISC) \\
\hline 9 & 1965 Mar. & 21 & 12 & 41 & 0 & 0 & 0 & - & $* *$ & $47 \mathrm{D} 19 \mathrm{C}$ & $\begin{array}{l}5.3 \text { (K), } \\
5.0 \text { (ISC) }\end{array}$ \\
\hline 10 & 1966 Nov. & 21 & 19 & 18 & $31 \pm 2$ & $7 \pm 5$ & $37 \pm 4$ & $\mathrm{P}$ & 35 & $15 \mathrm{D} 3 \mathrm{C}$ & 4.2 (ISC) \\
\hline 11 & 1967 Apr. & 5 & 7 & 57 & $11 \pm 2$ & $-13 \pm 3$ & $5 \pm 2$ & $\mathrm{p}$ & 39 & $16 \mathrm{D} 2 \mathrm{C}$ & 4.4 (ISC) \\
\hline 12 & 1967 Jun. & 17 & 11 & 51 & $13 \pm 4$ & $-11 \pm 6$ & $11 \pm 4$ & $\mathrm{P}$ & 16 & $7 \mathrm{D}$ & - \\
\hline 13 & 1967 Sep. & 19 & 5 & 46 & $32 \pm 4$ & $-39 \pm 5$ & $36 \pm 4$ & $\mathrm{P}$ & 16 & $10 \mathrm{D}$ & - \\
\hline 14 & 1968 Oct. & 31 & 10 & 9 & $10 \pm 4$ & $2 \pm 5$ & $8 \pm 4$ & $\mathbf{P}$ & 21 & $7 \mathrm{D} 2 \mathrm{C}$ & 3.8 (ISC) \\
\hline 15 & 1970 Apr. & 20 & 10 & 3 & $49 \pm 4$ & $-13 \pm 7$ & $48 \pm 5$ & $\mathrm{P}$ & 20 & $8 \mathrm{D} 5 \mathrm{C}$ & 3.9 (USCGS) \\
\hline 16 & 1970 Jun. & 11 & 11 & 45 & $15 \pm 3$ & $-8 \pm 3$ & $22 \pm 3$ & $\mathrm{P}$ & 291 & $15 \mathrm{D} 5 \mathrm{C}$ & 4.2 (USCGS) \\
\hline
\end{tabular}

Origin of coordinates; $136.90^{\circ} \mathrm{E}, 36.33^{\circ} \mathrm{N}$, and depth $=276 \mathrm{~km}$ (ISC hypocenter of No. 9). Directions toward east, north and up are taken as positive. Standard deviation of hypocenter is indicated by the numeral with \pm .*; number of data used for the hypocenter determination. **; 24 for PS and 36 for P. ***; numerical preceeding $\mathrm{C}$ or $\mathrm{D}$ indicates the number of compressions or dilatations, respectively. (A); present author, (K); KatsumatA (1970). P and PS indicate the uses of $\mathbf{P}$-wave arrival times and $\mathrm{S}-\mathrm{P}$ times, respectively. 
to the northeast of the EF. Together with the hypocenters of a few small events, it may be rather reasonable to assume the existence of another fault $\mathrm{E}^{\prime} \mathrm{F}^{\prime}$ parallel to $\mathrm{EF}$. During the preparation of this paper, an earthquake $(M=4.5)$ with the focal mechanism as expected occurred on August 14, 1973 at the northern end of the line $E^{\prime} F^{\prime}$ but it is not plotted on the figure because its precise location is not yet available. Thus, the distribution of the Takayama deep shocks demonstrates the existence of a major and a minor activefault planes that are consistent with the upper mantle structure as suggested in the preceding sections.

\section{Discussion and Conclusions}

In order to make it clear whether the Takayama deep shocks are really related to active faults or they are seemingly aligned along lines, migration of earthquake sequences with magnitudes greater than 5 and their relation to the vertical plane $E F$ or $E^{\prime} F^{\prime}$ were inspected. The most typical sequence is foreshocks associated to the greatest one of No. $7(M=7)$ on May 14, 1954. The first event (No. 4) occurred on December 6, 1951, the second (No. 5), on February 27, 1953 and the last (No. 6), on June 28, 1953. These together with the greatest one are connected by dashed lines in sequential order as shown in Fig. 13. Taking the inaccurate location of the second event (No. 5) into account, it may be concluded that these events verify the existence of an active fault within the slab. Another example was the first three shocks Nos. 1, 2 and 3 in Table 1. As shown in Fig. 13, these are not aligned along a line parallel to EF. The first event, however, may be independent to others because of the following reason. The last event (No. 3) occurred at a point on the extended slip-plane of the second event (No. 2). The greatest shock (No. 7) was also located on the extended slip-plane of the event No. 6. Therefore, it may be suggested that slip-plane produced by an earthquake is apt to stimulate the occurrence of next event. If this is true for the earthquake sequences in this area, the first event (No. 1) may be independent to others (Nos. 2 and 3), because the slip-plane of No. 1 did not orient toward the hypocenter of No. 2. Accordingly it seems that the seismic activity along the plane EF may be independent of the activity along the plane $E^{\prime} F^{\prime}$.

The next problem is concerned with the location of the active fault. A comparison of Fig. 13 with Fig. 2 indicates a certain discrepancy in location between the fault and the overlapped region indicated by $O B$ and $O C$ in Fig. 2. Although this discrepancy might not be significant considering the simplified model we have made on the upper mantle structure, the southwestern margin of the North Honshu slab may not extend so far as the active fault EF. If the fault plane is the real boundary between the North Honshu 
and Izu-Bonin slabs, those events occurred on the fault plane may be located at relatively shallower depths than those of neighboring events, because the descending slab in this area is supposed to form a crest as shown in Fig. 1b. The hypocenters on and near the main fault EF, however, are evidently deeper than those along $E^{\prime} F^{\prime}$ (Fig. 13). Therefore, the slab boundary may be located at $E^{\prime} F^{\prime}$ or to the further east. On the other hand, an earthquake beneath the Noto peninsula (see Fig. 9) showed the focal mechanism solution apparently characteristic to the North Honshu slab, which indicates that the slab boundary is located to the west of the Noto peninsula. Accordingly, the active fault EF may be located on the Izu-Bonin slab and is very close to the margin of North Honshu slab.

The general tectonics of the slabs may be inferred as follows: Owing to the conservation of surface area, the Pacific plate that underthrust beneath the central Japan corner is subjected to a lateral compression, by which a sharp lateral-bending of the plate should take place as was shown schematically in Fig. 1b. However, its deformation seems to be asymmetric with respect to the bent edge, since the volcanic front in south of Northeast Honshu is extremely curved. It may be a characteristic feature of arc-junction that the slabs, because of their particular configurations, are hard to descend at the bent edge without being separated. At greater depths, however, the sharp bending turns out to be the overlap of two slabs. Consequently, the lateral compression may be greatly reduced until it turns out to down-dip extension due to gravitational forces if the bent edge resists downward motion of the Izu-Bonin slab. The lack of similar earthquakes in the North Honshu slab may be explained by the difference in shape between both slabs, that Izu-Bonin slab is apparently plate-like than that of North Honshu slab, so that the gravitational force may be more effective in the former than in the latter. This may be a probable cause of the Takayama deep shocks. At further depths, however, the two slabs may be separated and the mechanical interaction between them will disappear. On the other hand, the sharp bending itself does not seem to increase seismic activities, because the bending has already begun near the junction of oceanic trenches so that the rate of bending may be very small. These earthquakes, therefore, may be confined to the range that the overlapped slabs can be mechanically coupled to each other. The observed range of the Takayama deep shocks is really about $90 \mathrm{~km}$ as shown in Fig. 13.

The writer wishes to express his thanks to Prof. T. Utsu, Dr. Y. Fukao and Mr. K. Ito of Nagoya University, not only for their interest but also for their valuable discussions. His thanks are also due to Dr. K. Oike of Kyoto University and to Dr. M. Katsumata of JMA for preparing some of seismological data. The writer also thanks Dr. T. Santo of Interna-
tional Institute of Seismology and Earthquake Engineering for his critical reading of the 
manuscript. The numerical calculations in this study were carried out by FACOM-230-60 at the computer center of Nagoya University (Problem Nos. 4001BP1006 and 4001CN0072).

\section{REFERENCES}

Aoki, H., T. Tada, Y. Sasaki, T. Oolda, I. Muramatu, H. Shimamura, and J. Furuya, Crustal structure in the profile across central Japan as derived from explosion seismic observations, J. Phys. Earth, 20, 197-223, 1972.

AOKI, H. and T. TADA, P-wave travel-time anomaly in Japan-Observation of the CANNIKIN nuclear explosion, J. Phys. Earth, 21, 433-443, 1973.

AOKI, H., Effect of pressure on the deformation of plate descending beneath island-arcs, Zisin (J. Seism. Soc. Japan), 27, 110-119, 1974 (in Japanese).

AKI, K., Crustal structure in Japan from the phase velocity of Rayleigh waves, 1 , Use of the network of seismological stations operated by the Japan Meteorological Agency, Bull. Earthq. Res. Inst. Tokyo Univ., 39, 255-283, 1961.

ANDo, M., Movement of the plate descending beneath Southwest Japan (abstract), presented at Meeting Seism. Soc. Japan, 1972.

Dobrin, M.B., Introduction to Geophysical Prospecting, 2nd ed., McGraw-Hill, 1960.

FrANK, F.C., Curvature of island arcs, Nature, 220, 368, 1968.

FUKAo, Y., Source process of a large deep-focus earthquake and its tectonic implicationsThe western Brazil earthquake of 1963, Phys. Earth Planet. Interiors, 5, 61-76, 1972.

Fuxao, Y., Seismological evidence for selectivity in slip planes under down-dip extension or compression, to be published in Geofisica International, 1974.

Grow, J.A. and A. QAmAR, Seismic wave attenuation beneath the central Aleutian Arc, Bull. Seism. Soc. Amer., 63, 2155-2166, 1973.

GUtenberg, B., The asthenosphere low velocity layer, Ann. di Geofis., 12, 439-460, 1959.

Herrin, E., 1968 seismological tables for P phases, Bull. Seism. Soc. Amer., 58, 1193-1241, 1968.

HILl, D.P., An earth-flattening transformation for waves from a point source, Bull. Seism. Soc. Amer., 62, 1195-1210, 1972.

HondA, H., A. MASATSUKA, and M. IchiKawa, On the mechanism of earthquakes and stresses producing them in Japan and its vicinity, 3, Geophys. Mag., 33, 271-279, 1967.

ICHIKAWA, M., Seismic activities at the junction of Izu-Mariana and southwestern Honshu arcs, Geophys. Mag., 35, 55-69, 1970.

ICHIKAWA, M., Reanalyses of mechanisms of earthquakes which occurred in and near Japan and statistical studies on the solutions obtained, 1926-1968, Geophys. Mag., 35, 207-274, 1971.

IsACKs, B. and J. Olryer, Seismology and the new global tectonics, J. Geophys. Res., 73, 5855-5899, 1968.

IsACKs, B. and P. Molnar, Distribution of stresses in the descending lithosphere from a global survey of focal-mechanism solutions of mantle earthquakes, Rev. Geophys. Space Phys., 9, 103-174, 1971.

IsHIDA, M., Seismicity and travel-time anomaly in and around Japan, Bull. Earthq. Res. Inst. Tokyo Univ., 48, 1023-1051, 1970.

Kanamori, H., Travel times to Japanese stations from Longshot and their geophysical implications, Bull. Earthq. Res. Inst. Tokyo Univ., 46, 841-859, 1968.

KANAMORI, H., Mantle beneath the Japanese arc, Phys. Earth Planet. Interiors, 3, 475-483, 1970.

KANAMORI, H., Tectonic implications of the 1944 Tonankai and 1946 Nankaido earthquakes, Phys. Earth Planet. Interiors, 5, 129-139, 1972. 
Katsumata, M, and L.R. Sykes, Seismicity and tectonics of the western Pacific: IzuMariana-Caroline and Ryukyu-Taiwan regions, J. Geophys. Res., 74, 5923-5948, 1969.

Katsumata, M., Seismicity and some related problems in and near the Japanese islands, Kenshinjiho (Quart. J. Seismol.), 35, 75-142, 1970 (in Japanese).

Le Pichon, X., Sea-floor spreading and continental drift, J. Geophys. Res., 73, 3661-3697, 1968.

Sleep, N.H., Teleseismic P-wave transmission through slabs, Bull. Seism. Soc. Amer., 63, 1349-1373, 1973.

Sorrells, G.G., J.B. Crowley, and K.F. Veith, Method for computing ray paths in complex geological structures, Bull. Seism. Soc. Amer., 61, 27-53, 1971.

SugimurA, A., Zonal arrangement of some geophysical and petrological features in Japan and its environs, J. Fac. Sci., Univ. Tokyo, 12, 133-153, 1960.

Sugimura, A., Plate boundaries in Japan and environs, Kagaku, 42, 192-202, 1972 (in Japanese).

TADA, T., P wave velocity distribution in the downgoing slab, Zisin (J. Seism. Soc. Japan), Ser. 2, 25, 310-317, 1972 (in Japanese).

UTsu, T., Seismological evidence for anomalous structure of island arcs with special reference to the Japanese region, Rev. Geophys. Space Phys., 9, 839-889, 1971.

UYEDA, S., Heat flow, in "The Crust and Upper Mantle of the Japanese Area", pp. 97-105, edited by the Japanese National Committee for Upper Mantle Project, Earthq. Res. Inst. Tokyo Univ., 1972.

Wadati, K., T. Hirono, and T. Yumura, On the attenuation of S-waves and the structure of the upper mantle in the region of Japanese Islands, Pap. Meteorol. Geophys. Tokyo, 20, 49-78, 1969. 